\title{
The Prevalence and Risk Factors of Limited Health Literacy in Iran: A Systematic Review and Meta-Regression Analysis
}

\author{
Seyed Hossein Mohaqeqi Kamal ${ }^{1}$, Mehdi Basakha ${ }^{1^{*}(\mathbb{D})}$, Homeira Sajjadi ${ }^{1}$ \\ 1. Dept. of Social Welfare Management, Faculty of Education Sciences and Social Welfare, University of Social Welfare and \\ Rehabilitation Sciences, Tehran, Iran
}

\begin{tabular}{l}
\hline Article Info \\
\hline dol 10.30699/jambs.26.118.1 \\
\hline $\begin{array}{l}\text { Received: } 2018 / 01 / 10 ; \\
\text { Accepted: } 2018 / 07 / 30 ; \\
\text { Published Online: } 01 \text { Sep } 2018 ;\end{array}$ \\
Use your device to scan and read the \\
article online \\
\end{tabular}

Corresponding Information: Dr. Mehdi Basakha, Dept. of Social Welfare Management, Faculty of Education Sciences and Social Welfare, University of Social Welfare and Rehabilitation Sciences, Tehran, Iran

Email: Me.basakha@uswr.ac.ir

\section{ABSTRACT}

There is a requisite need to document the health literacy status and its determinants for making recommendations for public health promotions. The aim of this study was to determine the prevalence of limited health literacy and its associated factors in Iranian studies. Search queries were made in PubMed, SCOPUS, SID, Irandoc, IranMedex, and Magiran from 2000 to 1 April 2016. The quality of the selected studies was assessed using the Critical Appraisal Skills Program checklists. Thirty one original papers were incorporated into the systematic review. We conducted a meta-analysis using a random effects model. All analysis were performed using comprehensive meta-analysis [CMA] V.2 statistical software. Thirty-one papers were reviewed including data on 28,138 subjects and reporting a prevalence of low health literacy between $4.8 \%$ and $79.9 \%$. Pooled analysis of these data showed that the weighted prevalence of low health literacy was $37.01 \%$ (95\% confidence interval [CI]: $36.97 \%, 37.04 \%$ ) and of marginal health, literacy was $30.76 \%$ (95\% CI: $30.72 \%, 30.79 \%$ ). Low educational levels, old age, poor employment situation, and low economic status were the most important determinants of limited health literacy. In the multivariate meta-regression model, the years of the studies were significantly associated with health literacy prevalence rates. Only a third of the population had adequate health literacy and health literacy was poor among vulnerable groups such as the unemployed, older and less educated people. So, considering appropriate strategies for each of these groups could have a significant role in improving community health literacy.

Keywords: Health literacy, Systematic review, Meta-Analysis, Regression analysis, Iran

(c) (1) Copyright $\odot$ 2018, This is an original open-access article distributed under the terms of the Creative Commons Attribution-noncommercial 4.0 International License which permits copy and redistribute of the material just in noncommercial usages with proper citation.

\section{Introduction}

Health illiteracy has been suggested as a worldwide problem and a global challenge for the 21 st century (1). Although there is no agreement on the definition of health literacy, most studies in this area rely on this definition: "the degree to which individuals have the capacity to obtain, process and understand basic health information needed to make appropriate health decisions" (2).

Furthermore, The World Health Organization (WHO), in the fifth world conference on health promotion in Mexico, defined health literacy as a cognitive and social skill, which promotes the individual's health by influencing their ability and motivation to acquire and utilize health information. To facilitate people's access to health information and improve their capacity in applying health information, health literacy should become a priority in health systems (3). In this regard, health literacy goes beyond a narrow concept of health education and individual behavior-oriented communication and addresses the environmental, political, and social factors that determine health. In the Mexico conference, it was emphasized that health literacy is not only a positive personal feature, but also one of the most important determinants of public health (4). The report of the WHO
Commission on the Social Determinants of Health (CSDH) has also advised countries to form a council of all stakeholders to develop and implement community health literacy strategies (5).

According to the American Center for Health Care Strategies, people with limited health literacy will have less ability to understand the health professionals' recommendations. As well as, they have a worse health condition (6), more utilization of hospital services (7, 8), more emergency health service needs (9), and lower ability to utilize prevent services (10). These individuals have also lower self-care skills (11). Furthermore, lower health literacy usually results in additional medical costs (12), and ultimately leads to an increase in the mortality rate (9). Even some researchers believe that health literacy is a stronger predictor for health status compared to variables such as age, income, employment status, education level, and race $(13,14)$.

Because of the importance of health literacy for developing countries, there is a requisite need to document the Iranian health literacy status and its 
determinants for making recommendations for public health promotions. To achieve this purpose, all studies related to Iranian health literacy were reviewed. There are a few articles showing different findings of the health literacy of the Iranian population. Thus, conducting a review study could detail the health literacy status in Iran and its determinants to provide a summarized knowledge for policymakers. In addition, since the studies have used different methods and assessment tools, they have reported different statuses for the Iranian health literacy issue. According to our literature review, the prevalence of low health literacy has been reported between $4.8 \%$ and $79.9 \%$. Thus, to draw attention to the importance of health literacy and using various articles about its situation among Iranians, a systematic review and meta-analysis was conducted. To the best of our knowledge, no such work has been carried out in Iran. The main questions raised in this study are as follows: (a) What is the mean score of health literacy; (b) What is the prevalence of limited health literacy, and (c) What are the risk factors of limited health literacy?

\section{Materials and Methods}

\section{This Study Design and Population}

In this meta-analysis, the study population included all studies that have examined various aspects of health literacy in the Iranian context.

\section{Search Strategy}

A systematic review was conducted to identify published articles on the health literacy situation in Iran. Quantitative studies were searched and downloaded from MEDLINE (PubMed), Scopus, SID (Scientific Information Database, www.sid.ir), Irandoc (Iranian Research Institute for Information Science and Technology, www.irandoc.ac.ir), IranMedex, and Magiran. An electronic search was performed with no specification of the language, including articles from 2000 to 1 April 2016. However, two keywords were used in the search query for English language databases: "health literacy" and "Iran". For Persian language databases, we only used one keyword "Savad e Salamat" (health literacy). Boolean operators were applied in this case. The unpublished studies were not considered; critical review of previous review articles was conducted to identify any missed relevant studies.

\section{Inclusion/Exclusion Criteria}

All papers' titles were initially screened by two reviewers. They decided on inclusion or exclusion of each study in the systematic review through an independent evaluation. In case of disagreement, the decision was made by entirety review of the article and a tripartite discussion among the researchers. Several inclusion criteria were considered for the systematic review; sampling from Iranian society, being quantitative study, study on health literacy and its determinants, and being in the range of 15 past years. These broad criteria were considered to allow the inclusion of a maximum number of qualified articles. Also, three criteria were considered for exclusion: a) irrelevant studies in terms of design and subject; b) studies with insufficient information and c) low-quality studies.

\section{Quality Assessment}

Quality assessment of the studies was carried out using Critical Appraisal Skills Program checklists (15). The methodological evaluation of the prevalence studies was performed by appraising the sample size, sampling method, and reliability and validity of the data collection tool. Another checklist for quantitative studies was utilized that assessed the appropriateness of the research design, the consideration of interventional variables in the study, accurate sampling method, and proper use of statistical analysis (e.g., correlation coefficients, the odds ratio, p-values, and confidence intervals). Assessing the quality of studies, eight of the 38 articles were excluded because they did not meet the minimum criteria for inclusion. These studies were excluded because of inadequate sample size (two articles), using unreliable and invalid questionnaires (two articles), and inappropriate sampling method (one article). In addition, three articles did not report the prevalence rate or confidence interval for their estimations and were eliminated from the article list. Qualitative assessments were independently evaluated by two reviewers, and in case of disagreement, they were referred to the third reviewer.

\section{Data Extraction}

A structured checklist was used for the extraction of information on the year of publication, study design, population, sample size, score, determinants, inclusion/exclusion criteria, sources of health information, and instruments. The mean score of health literacy for all studies was standardized to one hundred. Low health literacy was defined as the rate of subjects scoring lower than inadequate level in the Test of Functional Health Literacy in Adults (TOFHLA). In other questionnaires, scores of less than 60 percent of the maximum score were considered as low health literacy. Marginal literacy was defined as the rate of subjects scoring at the marginal level on versions of TOFHLA or at the seventh to eighth-grade levels on other measures. In this study, the limited health literacy indicating low and marginal health literacy.

\section{Statistical Analysis}

Pooled analyses were conducted by weighted means, that is, each study influenced the analyses in proportion to the size of the population in that study. The data were analyzed using meta-analysis with the random effects model. The heterogeneity of the studies was investigated using the $I^{2}$ index. The $I^{2}$ test showed that there were no significant differences between the findings of various studies. Therefore, the studies were homogeneous and could be used in the meta-analysis. Publication bias was assessed using the funnel plot. All analyses were performed using CMA Version 2.0 statistical software. 
The significance level of all tests was set at $\mathrm{P}$-value $<0.05$. Furthermore, meta-regression analysis was used to investigate the relationship between health literacy and the year of study, and sample size. Ethics approval was obtained from Ethic Committee of University of Social Welfare and Rehabilitation (No. IR.USWR. REC.1395.172).

\section{Results}

The electronic search yielded 308 studies from the searched databases. In the first stage of screening, duplicate papers were excluded and the remaining 128 articles entered the second stage of screening. The inclusion criteria for the second stage of screening were relevancy with the subject matter and removed the papers that were published simultaneously in Persian and English. Thirty-eight articles passed the second stage of screening. It should be noted that in the first stage, abstracts, and in the second stage, full-text articles were evaluated by two reviewers. In assessing the quality of studies, of the total 38 articles, eight articles did not meet the minimum quality criteria and were excluded. Correspondingly, the reference lists of the remaining papers were hand-searched and one additional study was identified as relevant. Finally, a synthesis of 31 quantitative studies was considered qualified after the review process, an illustration of which is provided in Figure 1.

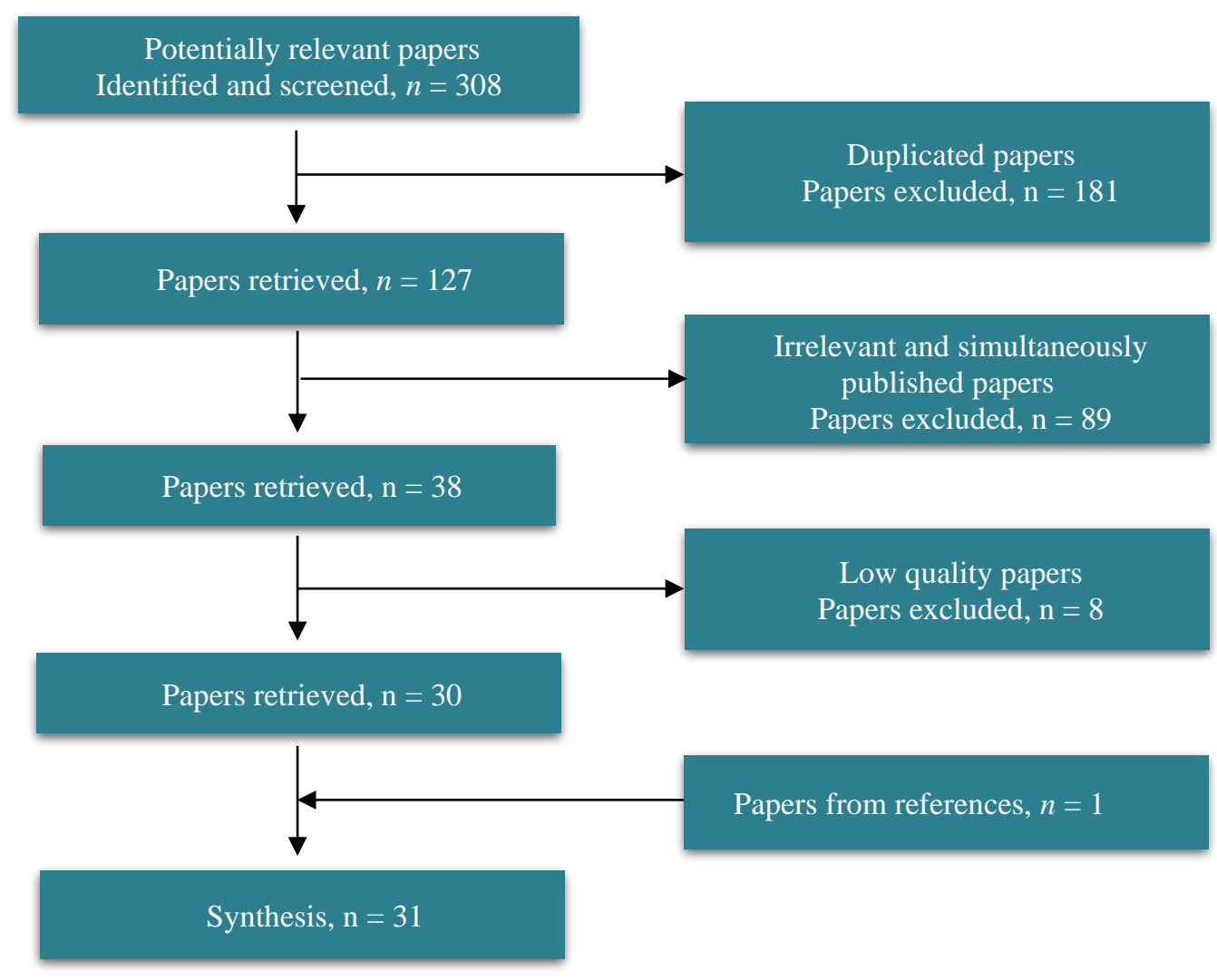

Figure 1. The process of screening the articles for systematic review

The results are presented under four sections namely mean score of health literacy (31 papers), the prevalence of limited health literacy (23 papers), risk factors of limited health literacy (21 papers), and metaregression (31 papers).

\section{The Mean Score of Health Literacy}

A total of 31 studies were assigned to the mean status of health literacy and their key features are summarized in Fig. 2. Among the studies, fourteen articles (9, 1628) applied the Test of Functional Health Literacy in Adults (TOFHLA). Seven articles (29-35) used Health
Literacy for Iranian Adults (HELIA), three articles (3638) used the short form of TOFHLA, three articles (3941) used self-made questionnaires, and Chew's health literacy questionnaire (42), AIDS literacy (43), the Newest Vital Sign (NVS) (44), and the functional, relational and critical health literacy questionnaire (45) were used in separate articles. In one study (36), the NVS and short form of TOFHLA instruments were used together. It should be noted that one article (37) used the Rapid Estimate of Adult Health Literacy in Medicine (REALM) questionnaire concurrently with TOFHLA. 


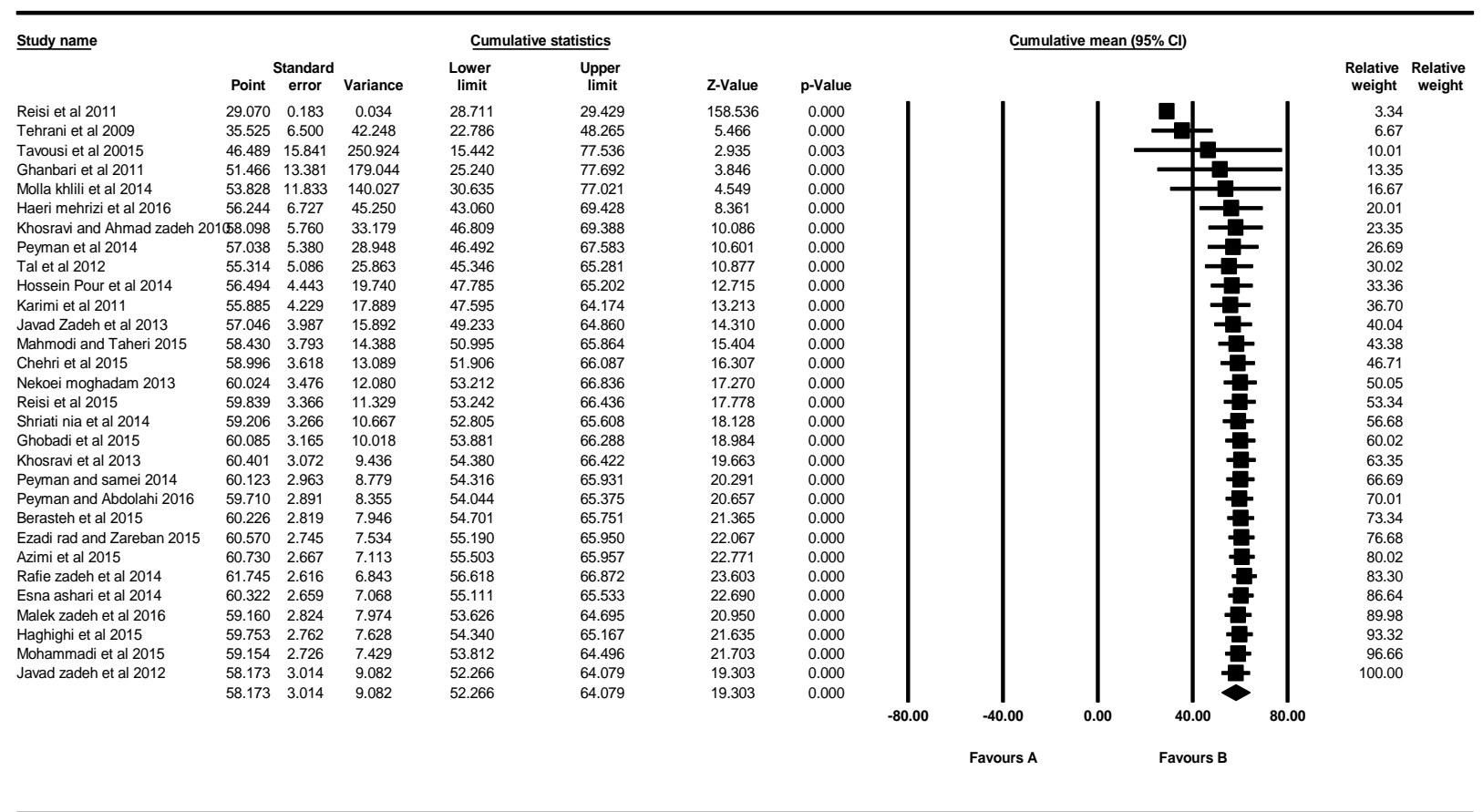

Meta Analysis

Figure 2. The standardized mean score for health literacy (Original table)

According to Figure 2, the pooled analyses of the data on 28,138 subjects showed that the weighted score of health literacy was 58.18 out of 100 (95\% CI: $58.14 \%, 58.21 \%$ ). Furthermore, Figure 3 shows an acceptable symmetry in the funnel plot, which indicates the publication, was unbiased.

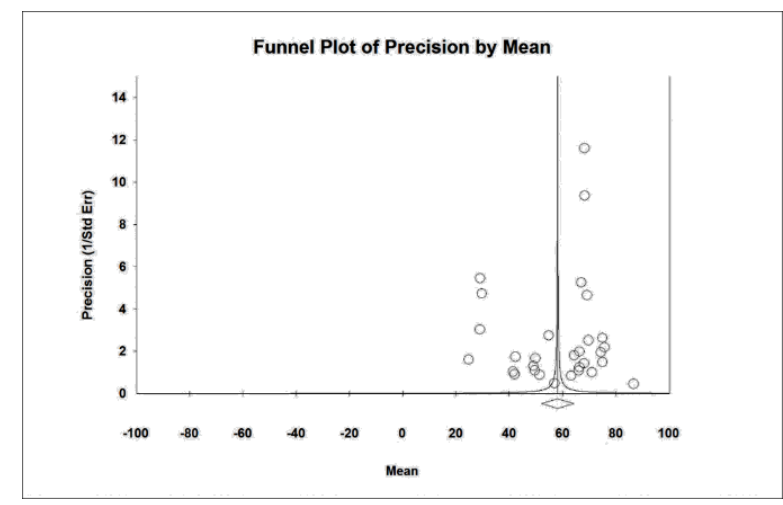

Figure 3. Funnel plot related to health literacy studies in Iran (Original figure)

\section{The Prevalence of Limited Health Literacy}

A total of 23 studies were assigned to the prevalence of limited health literacy. Pooled analyses of these data on 19,351 subjects showed that the weighted prevalence of low health literacy was $37.01 \%$ (95\% CI: $36.97 \%$,
$37.04 \%$ ) and of marginal health, literacy was $30.76 \%$ (95\% CI: 30.72\%, 30.79\%).

\section{The Risk Factors of Limited Health Literacy}

Of the 31 articles related to health literacy, 21 articles investigated the risk factors of limited health literacy. Among the articles, eight factors were identified as the risk factors of limited health literacy. Among the factors, low educational levels (19 papers), old age (12 papers), poor employment situation (seven papers), sex (in six studies being women and in two studies being men), low economic status including low-income (in six papers), being single (in two papers), and poor access to medical care (in one paper) were the major determinants of limited health literacy.

\section{Meta-regression Analysis}

According to Figure 4, the positive slope of the Metaregression line $(P=0.27)$ shows that health literacy is rising with a slow slope, but it is not statistically significant. In other words, the level of health literacy remained relatively consistent by increasing the sample size. Furthermore, there is a significant relationship $(P=0.00)$ between health literacy and the year of study (Figure 5). 


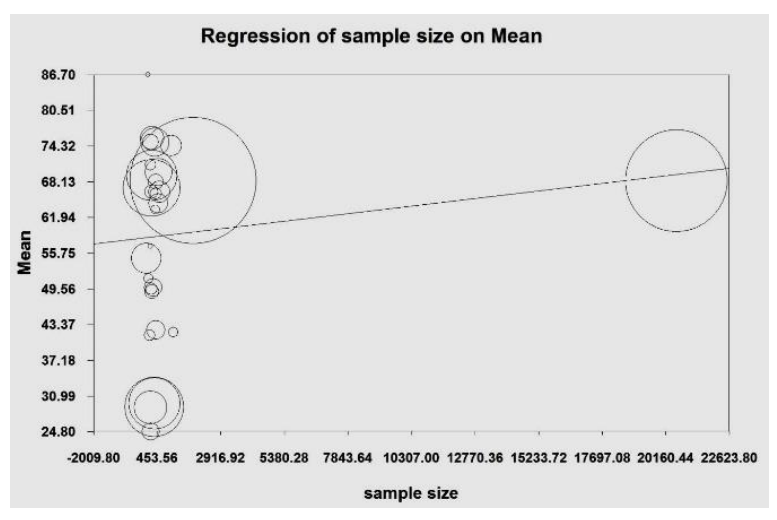

Figure 4. The relationship between health literacy and the sample size using meta-regression (circle size is proportional to sample size). (Original figure)

\section{Discussion}

In this study, it was shown that only one-third of the population had adequate health literacy. Generally, studies in other countries also show widespread inadequate health literacy, especially in developing countries. For example, Paasche-Orlow et al. (2015) in a systematic review in the United States showed that the weighted prevalence of low health literacy was $26 \%$ (95\% CI: $22 \%, 29 \%$ ) and of marginal health literacy was $20 \%$ (95\% CI: 16\%, 23\%) (46). Also, Sahm et al. (2012) in a national sample of Irish adults showed that limited health literacy ranged from $18.4 \%$ and $57.2 \%$ (47). In addition, Wu et al. (2017) evaluated the prevalence of low health literacy and demographic associations in Shanghai, China. Their study results showed that the prevalence of low health literacy was $84.49 \%$ (95\% CI, $82.56 \%$ to $86.41 \%$ ) (48).

As expected, the health literacy rate increases with increasing educational level. This relationship was previously reported in numerous studies $(9,49,50)$. This study highlights that based on the number of studies, the impact of the educational level is more profound compared to the other determinants of health literacy. In addition, as well as the results of other studies $(9,51-53)$, there is a significant relationship between socioeconomic status and the level of health literacy. This means that the higher the socioeconomic status, the greater the average level of health literacy. The results of the Wu et al. (2017) showed that the prevalence of low health literacy was negatively associated with the level of education, occupation, and annual household income (48).

Furthermore, there is a significant relationship between health literacy and the year of study. In other words, the level of health literacy has been rising during the study period (2007-2016). It seems that the increase in education in this period has had a positive impact on the health literacy level.

This article is subject to several limitations. Qualitative, unpublished and gray literature, CINAHL and ISI databases, and non-Iranian studies were not investigated in this review. Furthermore, this study

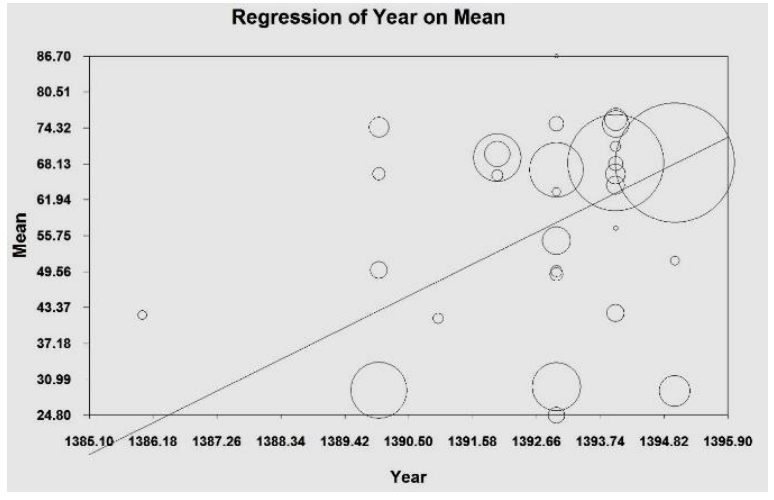

Figure 5. The relationship between health literacy and the year of study using meta-regression (circle size is proportional to sample size). (Original figure)

presented an estimate of the prevalence of limited health literacy in Iranian studies. However, the representativeness of these studies for the whole country cannot be guaranteed.

\section{Conclusion}

This study indicates inadequate health literacy in Iran, especially in vulnerable groups such as the elderly, people with lower education, and unemployed. Therefore, achieving health equity requires not only the identification of vulnerable health illiterate groups, but also finding ways to reduce the origins of restriction on their access to health information. Thus, health promotion programs in Iran should pay more attention to health literacy among the target population. In this regard, education of health care workers, use of the mass media and distribution of written materials in community health centers are recommended to promote health literacy in the society.

\section{Acknowledgment}

The study was sponsored by the deputy of research and technology, University of Social Welfare and Rehabilitation Sciences. Therefore, we sincerely thank the collaboration of the authorities of the university.

\section{Conflict of Interest}

No conflict of interest is declared.

\section{Funding}

The study was funded by Vice-chancellor for Research and Technology, University of Social Welfare and Rehabilitation Sciences (No. 95/801/T/19603).

\section{References}

1. Nutbeam D, Kickbusch I. Advancing health literacy: a global challenge for the 21 st century. Health promotion international. 2000;15(3):183-4. https://doi.org /10.1093/heapro/15.3.183 
2. Ratzan SC PR. Introduction. In: Selden CR ZM, Ratzan SC, Parker RM, editor. National Library of Medicine Current Bibliographies in Medicine: Health Literacy National Institutes of Health, U.S. Department of Health and Human Services; 2000.

3. WHO, editor Health literacy and health behaviour. 7th Global Conference on Health Promotion: track themes; 2009; Kenya.

4. Kichbush I. translators: Sarmast H, Moosavian poor M. Health literacy and discussion on health and education Publication of Health Promotion and Healthy Lifestyle Association. 2006;2:4.

5. CSDH. Closing the gap in a generation: health equity through action on the social determinants of health: final report of the commission on social determinants of health. 2008 .

6. JCNHES. Achieving Health Literacy: An investment in the Future. Atlanta, Ga: Joint Committe on National Health Education Standards, American Cancer Society; 1995.

7. Baker DW, Gazmararian JA, Williams MV, Scott T, Parker RM, Green D, et al. Functional health literacy and the risk of hospital admission among Medicare managed care enrollees. American journal of public health. 2002;92(8):1278-83. https://doi.org/10.2105 /AJPH.92 .8.1278 PMid:12144984 PMCid:PMC1447230

8. Baker DW, Parker RM, Williams MV, Clark WS, Nurss J. The relationship of patient reading ability to selfreported health and use of health services. American journal of public health. 1997;87(6):1027-30. https://doi.org/10.2105/AJPH.87.6.1027 PMid:9224190 PMCid:PMC1380944

9. Javadzade H, Reisi M, Mostafavi F, Sharifirad G, Radjati F, Hasanzade A. Relationship between health literacy, health status, and healthy behaviors among older adults in Isfahan, Iran. Journal of Education and Health Promotion. 2012;1(1):31. https://doi.org/10. 4103/2277-9531.100160 PMid:23555134 PMCid:PMC3577376

10. Scott TL, Gazmararian JA, Williams MV, Baker DW. Health literacy and preventive health care use among Medicare enrollees in a managed care organization. Medical care. 2002;40(5):395-404. https://doi.org /10.1097/00005650-200205000-00005 PMid:11961474

11. Schillinger D, Grumbach K, Piette J, Wang F, Osmond $\mathrm{D}$, Daher C, et al. Association of health literacy with diabetes outcomes. JAMA. 2002;288(4):475-82. https://doi.org/10.1001/jama.288.4.475

PMid:12132978

12. Howard DH, Sentell T, Gazmararian JA. Impact of health literacy on socioeconomic and racial differences in health in an elderly population. Journal of general internal medicine. 2006;21(8):857-61. https://doi.org/ 10.1111/j.1525-1497.2006.00530.x PMCid:PMC1831584

PMid: 16881947

13. van der Heide I, Wang J, Droomers M, Spreeuwenberg P, Rademakers J, Uiters E. The Relationship Between Health, Education, and Health Literacy: Results From the Dutch Adult Literacy and Life Skills Survey. Journal of Health Communication. 2013;18(sup1):172-84. https://doi.org/10.1080/10810730.2013.825668 PMid:24093354 PMCid:PMC3814618

14. Adams RJ, Stocks NP, Wilson DH, Hill CL, Gravier S, Kickbusch I, et al. Health literacy: a new concept for general practice? Australian family physician. 2009;38(3): 144

15. CASP U. Critical Appraisal Skills Programme (CASP) 2014 Oxford: CASP Checklists; 2014 [

16. Khosravi A, Ahmadzadeh K, Arastoopoor S, Tahmasebi R. Assessing the Readability of Patient Education Materials about Diabetes Available in Shiraz Health Centers. Iranian Journal of Medical Education. 2014;14(8):661-7.

17. Tehrani S-A, Amirkhani MA. Health literacy and the influencing factors: a study in five provinces of Iran. 2007.

18. Ghanbari S, Majlessi F, Ghaffari M, Mahmoodi Majdabadi M. Evaluation of health literacy of pregnant women in urban health centers of Shahid Beheshti Medical University. Medical Daneshvar. 2012;19(97):1-12.

19. Khosravi A, Ahmadzadeh K. Investigating health literacy Level of patients referred to Bushehr hospitals and recognizing its effective factors. 2016.

20. Mohseni M, Khanjani N, Iranpour A, Tabe R, Borhaninejad V. Investigate the relationship between health literacy and health status among elderly people in Kerman-2013. Iranian Journal of Ageing. 2015;10(2):0-

21. Mollakhalili H, Papi A, Zare-Farashbandi F, Sharifirad G, HasanZadeh A. A survey on health literacy of inpatient's educational hospitals of Isfahan University of Medical Sciences in 2012. Journal of education and health promotion. 2014;3(1):66.

22. Peyman N, Samiee K. Investigating the status of health literacy among health providers of rural area. Journal of Health Literacy. 2016;1(1):46-52.

23. Tol A, Pourreza A, Rahimi Foroshani A, Tavassoli E. Assessing the effect of educational program based on small group on promoting knowledge and health literacy among women with type 2 diabetes referring to selected hospitals affiliated to Tehran University of Medical Sciences. Razi Journal of Medical Sciences. 2013;19(104):10-9.

24. Malekzadeh S, Azami M, Mirzaei M, Motamedi F. Comparative Investigation of Health Literacy Level of Cardiovascular Patients Hospitalized in Private and 
Educational Hospitals of Kerman City, Iran. Acta Inform Med. 2016;24(1):56-60. https://doi.org/10.5455 laim.2016.24.56-60 PMid:27041812 PMCid: PMC4789678

25. Mohammadi Z, Banihashemi AT, Asgharifard H, Bahramian M, Baradaran HR, Khamseh ME. Health literacy and its influencing factors in Iranian diabetic patients. Medical journal of the Islamic Republic of Iran. 2015;29:230.

26. Nekoei-Moghadam M, Parva S, Amiresmaili M, Baneshi M. Health Literacy and Utilization of health Services in Kerman urban Area 2011. Tolue Behdasht Journal. 2012;11(14):123-34.

27. Seyedoshohadaee M, Barasteh S, Jalalinia F, Eghbali M, Nezami M. The relationship between health literacy and self-care behaviors in patients with type 2 diabetes. Iranian Journal of Nursing Research. 2016;10(4):43-51.

28. Reisi M, Mostafavi F, Hasanzadeh A, Sharifirad G. The Relationship between Health Literacy, Health status and Healthy behaviors among Elderly in Isfahan. Health System Research. 2011;7(4):469-80.

29. Afshari M, Khazaei S, Bahrami M, Merati H Investigating Adult Health Literacy in Tuyserkan City. Journal of Education And Community Health. 2014;1(2):48-55. https://doi.org/10.20286/jech-010248

30. Haeri A TM, Rafieifar Sh, Soleimanian A, Sarbandi F, Ardestani M, Hashemi A and Montazeri A. The factor analysis of the urban population's health literacy. Payesh. 2016;15(3):251-7.

31. Haghighi ST, Lamyian M, Granpaye L. Assessment of the level of health literacy among fertile Iranian women with breast cancer. Electronic physician. 2015;7(6):1359.

32. Izadirad H, Zareban I. The Relationship of Health Literacy with Health status, Preventive Behaviors and Health services Utilization in Baluchistan, Iran. Journal of Education and Community Health. 2015;2(3):43-50. https://doi.org/10.20286/jech-02036

33. Mahmoodi $\mathrm{H}$, Negarandeh $\mathrm{R}$, Javaheri $\mathrm{M}$, Sharifi $\mathrm{P}$, Ghanei R, AminPour A, et al. EXAMINING THE RELATION OF HEALTH LITERACY WITH OUTCOMES OF DIABETES AMONG TYPE 2 DIABETES PATIENTS IN SAQEZ, WESTERN IRAN, 2011. Journal of Urmia Nursing and Midwifery Faculty. 2014;12(1):56-62.

34. Rafizadeh Sh TB, Hassanjani S, Razavi M, Amjady M, and Hojjati H. . Relationship between the Health Literacy with self-efficacy of the diabetic patient's type 2referred to Gorgan city clinic in 2014. . Journal of Diabetes Nursing. 2014;3(2):30-42.

35. Tavoosi M HA, Rafieifar Sh, Soleimanian A, Sarbandi F, Ardestani M, Hashemi A and Montazeri A. Iranian Adult Health Literacy: A National Study. Payesh. 2016;15(1):95-102.
36. Javadzade H, Sharifirad G, Reisi M, Tavassoli E, Rajati F. Health Literacy among Adults of Isfahan. Iran J Health Syst Res. 2013;9(5):540-9.

37. Peyman N, Abdollahi M. The relationship between health literacy and self-efficacy physical activity in postpartum women. Journal of Health Literacy. 2016;1(1):5-12.

38. Qobadi M, Besharat M, Rostami R, Rahiminezhad A, Pourgholami M. Health literacy, negative emotional status, and self-care behaviors in dialysis. Journal of Fundamentals of Mental Health. 2015;17(1):46-51.

39. Chehri ME, Najafi Mehri S, Ebadi A, Sarhangi F. Assessing the health literacy level of parents of preschool children. Iran J Pediatr Nurs. 2015;4(1):1-0.

40. Esna Ashari F, Pirdehghan A, Rajabi F, Sayarifard A, Ghadirian L, Rostami N, et al. The Study of Health Literacy of Staff about Risk Factors of Chronic Diseases in 2014. Scientific Journal of Hamadan University of Medical Sciences. 2015;22(3):248-54.

41. Karimi S, Keyvanara M, Hosseini M, Jazi M, Khorasani E. The relationship between health literacy with health status and healthcare utilization in 18-64 years old people in Isfahan. Journal of Education and Health Promotion. 2014;3(1):75-.

42. Peyman N, Behzad F, Taghipour A, Esmaily H. Evaluation of communication between healthcare workers and patients with chronic diseases according to their levels of health literacy. Journal of Research \&amp; Health. 2014;4(1):599-607.

43. Shariatinia S, Fararoei M, Karimzadeh Shirazi K, Shams M. Assessment of HIV/AIDS literacy in 15-49 years old people in Yasuj and its related factors. Armaghane danesh. 2015;19(12):1082-95.

44. Azimi S, Ramezankhani A, Ghafari M, Rakhshani F, Ghanbari S. Comparison of health literacy between medical and non-medical students in Shahid Beheshti Universities in the academic year 92-93. Pajoohandeh Journal. 2015;20(2):78-85.

45. Reisi M, Mostafavi F, Javadzade SH, Mahaki B, Sharifirad G. Assessment of Some Predicting Factors of Self-efficacy in Patients with Type 2 Diabetes. Iranian Journal of Endocrinology and Metabolism. 2015;17(1):44-52. https://doi.org/10.5001/omj.2016.10 PMid:26813680 PMCid:PMC4720937

46. Paasche-Orlow MK, Parker RM, Gazmararian JA, Nielsen-Bohlman LT, Rudd RR. The prevalence of limited health literacy. Journal of general internal medicine. 2005;20(2):175-84. https://doi.org/10.1111/ j.1525-1497.2005.40245.x PMid:15836552PMCid: PMC1490053

47. Sahm LJ, Wolf MS, Curtis LM, McCarthy S. Prevalence of limited health literacy among Irish adults. Journal of health communication. 2012;17(sup3):100-8. 
https://doi.org/10.1080/10810730.2012.718041 PMid:23030564

48. Wu Y, Wang L, Cai Z, Bao L, Ai P, Ai Z. Prevalence and risk factors of low health literacy: A communitybased study in Shanghai, China. International journal of environmental research and public health. 2017;14(6):628. https://doi.org/10.3390/ijerph14060 628 PMid:28604645 PMCid:PMC5486314

49. Baker DW. The meaning and the measure of health literacy. Journal of general internal medicine. 2006;21(8):878-83. https://doi.org/10.1111/j.15251497.2006.00540.x PMid:16881951 PMCid: PMC1831571

50. Nielsen-Bohlman L PA, Kindig DA. Health Literacy: A Prescription to End Confusion. Washington (DC): National Academies Press; 2004. Available from: http://www.ncbi.nlm.nih.gov/books/NBK216035.
51. Sun X, Shi Y, Zeng Q, Wang Y, Du W, Wei N, et al. Determinants of health literacy and health behavior regarding infectious respiratory diseases: a pathway model. BMC public health. 2013;13(1):1. https://doi.org/10.1186/1471-2458-13-261 PMid:23521806 PMCid:PMC3621712

52. Hoffman S, Marsiglia FF, Nevarez L, Porta M. Health Literacy among Youth in Guatemala City. Social Work in Public Health. 2016:1-8. https://doi.org/10.1080/ 19371918.2016.1188741 PMid:27392315

53. Hussein SH, Almajran A, Albatineh AN. Prevalence of health literacy and its correlates among patients with type II diabetes in Kuwait: A population-based study. Diabetes research and clinical practice. 2018;141:118 25. https://doi.org/10.1016/j.diabres.2018.04.033 PMid:29729374

\section{How to Cite This Article:}

Mohaqeqi Kamal S H, Basakha M, Sajjadi H. The Prevalence and Risk factors of Limited Health Literacy in Iran: a Systematic Review and Meta-regression Analysis. J Adv Med Biomed Res. 2018; 26 (118):1-8

\section{Download citation:

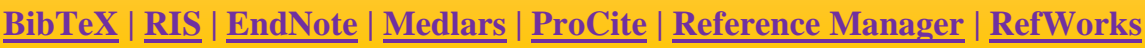

\section{Send citation to:}

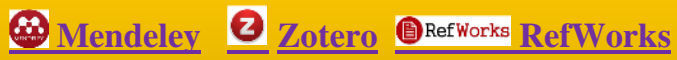

